\title{
A model for exchange rates with crawling bands: an application to the Colombian peso
}

Article

Accepted Version

Brooks, C. and Revéiz, A. (2002) A model for exchange rates with crawling bands: an application to the Colombian peso. Journal of Economics and Business, 54 (5). pp. 483-503. ISSN 0148-6195 doi: https://doi.org/10.1016/S0148-6195(02)001030 Available at https://centaur.reading.ac.uk/24162/

It is advisable to refer to the publisher's version if you intend to cite from the work. See Guidance on citing.

To link to this article DOI: http://dx.doi.org/10.1016/S0148-6195(02)00103-0

Publisher: Elsevier

All outputs in CentAUR are protected by Intellectual Property Rights law, including copyright law. Copyright and IPR is retained by the creators or other copyright holders. Terms and conditions for use of this material are defined in the End User Agreement.

www.reading.ac.uk/centaur

\section{CentAUR}


Central Archive at the University of Reading

Reading's research outputs online 
NOTICE: this is the author's version of a work that was accepted for publication in the Journal of Economics and Business. Changes resulting from the publishing process, such as peer review, editing, corrections, structural formatting, and other quality control mechanisms may not be reflected in this document. Changes may have been made to this work since it was submitted for publication. A definitive version was subsequently published in the Journal of Economics and Business, 54.5 (2002), DOI: 10.1016/S01486195(02)00103-0 


\title{
A Model for Exchange Rates with Crawling Bands - An Application to the Colombian Peso
}

\author{
Chris Brooks and Alejandro Revéiz H.
}

The authors are both members of the ISMA Centre, PO Box 242, University of

Reading, Whiteknights, Reading, Berks, RG6 6BA, UK. Tel: (+44) (0) 11893167 68; Fax: (+44)(0) 1189314741.

Acknowledgements

We would like to thank two anonymous referees and an Editor of this journal (J. Choi) for useful comments on a previous version of this paper. The usual disclaimer applies.

August 2001

\begin{abstract}
This paper builds upon previous research on currency bands, and provides a model for the Colombian Peso. Stochastic differential equations are combined with information related to the Colombian currency band to estimate competing models of the behaviour of the Colombian Peso within the limits of the currency band. The resulting moments of the density function for the simulated returns describe adequately most of the characteristics of the sample returns data. The factor included to account for the intra-marginal intervention performed to drive the rate towards the Central Parity accounts only for $6.5 \%$ of the daily change, which supports the argument that intervention, if performed by the Central bank, it is not directed to push the currency towards the limits. Moreover, the credibility of the Colombian Central Bank, Banco de la República's ability to defend the band seems low.
\end{abstract}

Keywords: Exchange rate, crawling band, monetary policy.

J.E.L. References: F31, E58, C22 


\section{Introduction}

Traditionally, when defining exchange rate policy, Central Banks (CB) have broadly used either a floating rate model, in which the rate is not controlled, or a fixed rate model. In the latter, the Authorities have to sell or buy their own currency in the exchange markets in order to maintain the ex-ante predetermined value. Currency bands or target zones, a third alternative which has been recently implemented by some countries, are a compromise between these two options in which the $\mathrm{CB}$ allows the exchange rate to fluctuate between some predefined boundaries. At the top (bottom) of the band, the Central Bank will buy (sell) its currency in the exchange market to keep the rate within the limits of the band. In the latter case, the model 'operates as a fixed parity system under increasing pressure'. Within the band, the exchange rate fluctuates freely ${ }^{\mathrm{ii}}$, operating more like a floating rate mechanism. Unmanaged floating has been argued to be undesirable for two reasons (Williamson, 1986, 1987). First, the treatment of exchange rates as a "residual" of macroeconomic policy can lead to potentially serious currency misalignments. Thus the real exchange rate can deviate from its fundamental equilibrium rate for a prolonged period. Second, pure floating does not provide encouragement for countries to co-ordinate their economic policies.

Monetary arrangements such as currency bands or target zones have a significant level of effective complexity. They are partly the result of an apparently regular set of information, and a stochastic proportion. The analysis of agents' expectations in such a context is difficult as the future expected value of the currency is conditioned by the effective and potential complexity of the political and economic system. These factors preclude any direct estimation of econometric models, as the forcing process is frequently unobservable (see Cumby and van Wijnbergen, 1989). Given the complexity of the forcing process, models for currency bands express the exchange rate as a function of the fundamentals, which in turn evolve according to a stochastic process.

Krugman's canonical model (Krugman, 1991 and 1992) assumes that such process is governed by a random walk. The solution to the resulting stochastic differential equation is constrained by a tangency condition to the limits of the bands. This model implicitly assumes that modification to the stock of the monetary base is only performed by the Authorities in the limits of the band by means of selling or buying their own currency. Extensions to the basic model, in particular by modifying the underlying process followed by the fundamentals, have been widely used. These include adding a trend term or a coefficient of mean reversion. Developing countries in particular can suffer severely from exchange rate instability or protracted deviations from exchange rate fundamentals (see Meltzer, 1996 for a discussion of the various exchange rate regime options available in the context of developing economies).

A crawling band is a particular form of target zone where the band and the central parity within that band follow some pre-announced rate of change. Williamson (1987) defines a crawling 
band as "a wide band that moves slowly with a view to keeping the exchange rate in line with fundamentals". There are several types of crawling band (see Canterbery and Boorman, 1970). The adoption of an explicit nominal exchange rate crawling band in Colombia in $1994^{\mathrm{iii}}$ responded to the implementation of a stabilisation model based on control of the monetary base in order to lower inflation. The main argument to support the case of an exchange rate band in Colombia was that allowing the nominal exchange rate to fluctuate within a band gives monetary flexibility to the Central Bank, while anchoring the market's expectations. Crawling bands allow for a compromise between monetary flexibility (for the now independent Central Bank in order to fulfil its new constitutional obligation ${ }^{\text {iv }}$ ) and some degree of certainty for the private sector and the government.

However, such a choice is not cost free as the management by the authorities of this exchange system is very difficult. This is the price paid to give more certainty to economic agents, as an analysis of agents' expectations in such context is very complex as the future expected value of the rate, and therefore its present value, is conditioned upon the effective and potential degree of intervention. It is also worth noting that the crawling band was the last resort as an exchange rate regime. It yielded value as a real option to keep strategic possibilities open between the periods of liberalisation and structural reform of the economy, and the right time to introduce a free floating system. Urrutia (1981) discusses the Colombian experience with the crawling peg, arguing that it represented a system of mini-devaluations which were never explicitly discussed by the government but were left to the discretion of the monetary authorities. Numerous other studies have also sought to describe qualitatively the behaviour of the money supply, interest rates and exchange rates in Colombia (e.g. Edwards, 1985, 1986; Bandera and Lucken, 1985).

Research on exchange rate target zones and regime switching based on the application of stochastic calculus theory includes models of currency bands (Krugman, 1997); currency bands under limited reserves (Krugman and Rotemberg, 1992); speculative attacks on target zones (Krugman and Rotemberg, 1990 and Flood and Garber, 1989); speculative attacks on fixed exchange rate regimes (Buiter and Grilli, 1992 or Levin, 1975); intervention policy analysis (Bertola and Caballero, 1992) as well as techniques for the estimation and testing of exchange rate target zones and process switching (Smith and Spencer, 1992). The latter proposes the use of the Method-of-Simulated-Moments (MSM) and a grid-search procedure in order to estimate simulated moments that are then compared to the observed sample moments.

This article uses the same method as Smith and Spencer (1992) to generate the observed moments for the Colombian Peso. However, our paper includes several important innovations. First, the underlying process includes mean reversion and regime switching volatility. These are both stylised features of foreign exchange rates subject to a crawling band, which should 
be incorporated into any statistical model of such a series, but which preclude an analytical solution. A numerical approximation is therefore used. Novel is our definition of the moments of the loss function as they include the proportion of time spent in each regime. Second, most of the existing literature as focused on European currencies. This paper studies the case of an emerging market, Colombia, for which, contrary to more developed markets, potential intervention is significant in terms of market turnover (close to $100 \%$ of the market for some days in December 1996 for example) and the signalling channel seems to be less effective. The Colombian case is also particularly interesting since the Colombian peso (COP) has been placed under unusual pressures as a result of de facto dollarization over the past twenty years or so (see Reennhack and Mondino, 1988; Kamas, 1985). Moreover, given the transparency of the monetary policy, results can be compared with Authorities' targets yielding a measure of intervention effectiveness, and of the Central Bank's ability to defend the band. We thus provide a model that is able to track the stochastic features of the exchange rate.

The remainder of this paper comprises 4 sections. The second section describes the mechanism set up by Banco de la Republica at the beginning of 1994 to execute the monetary policy. In the third section, a preliminary statistical analysis of the Colombian Peso (COP) is presented. The basic model for crawling bands is then developed in section 4 . The fifth section explains the estimation results and conclusions. Finally, the estimation procedure and discrete approximations to the stochastic differential equation are detailed in an appendix.

\section{Implementation of the monetary policy}

\subsection{Operating procedures}

In order to reduce inflation, from January 1994 to September 1999, Banco de la República periodically set 3 bands: a Monetary Base Corridor, an Exchange Rate Band and an Interest Rate Range. The desired evolution of the monetary base (coherent with the inflation target) is used as a reference for the execution of the Open Market Operations. Intervention in the exchange market was executed in order to avoid the rate crossing the limits imposed by the Authorities $^{v}$. In addition, in order to decrease the volatility of the interest rate, the Central Bank sets a floor and a cap to the very short-term Repo and overnight rates. This is achieved by expanding or contracting the monetary base through Open Market Operations when the rate touches either the top or the bottom of the predetermined range.

Although this system gave the Central Bank a considerable degree of flexibility, these 3 constraints on the main economic variables can be conflictive, forcing the Authorities to drop or modify one or more of the bands. Friction between the foreign exchange and monetary goals will arise if while selling securities to the financial system (monetary contraction), the central bank - in its commitment to defend the bottom of the band - has to buy dollars, which results in a monetary expansion. This could prevent the central bank from attaining its objective of lowering the inflation rate, as the amount of liquidity in the economy cannot be easily limited. 
Conflicts can also arise when the exchange rate touches the top of the band as dollar sales reduce the monetary base. Obviously, contradictions between monetary objectives and interest rate ranges can easily appear. To partially avoid these, the Central Bank's Board gave priority to the monetary base (in line with the Constitution) but the ambiguity of how and under which conditions this hierarchy was applied added more uncertainty. In this context, realignment probabilities were affected by many factors: the level of reserves, other macroeconomic variables and also the agents' perceptions concerning the complexity of the politic and economic arrangement, which in turn determined the evolution of the fundamentals.

\subsection{Crawling Band Implementation}

The foreign exchange band mechanism is usually defined by the determination of 4 factors: the reference for the nominal rate, the central parity, the crawling rate and the band's width. More than $70 \%$ of Colombian peso (COP) external trade and approximately the same proportion of the stock and service of external debt is denominated in US dollars. Hence the reference for the nominal exchange rate has traditionally been in that currency.

For the Central Parity, Banco de la Republica decided that the exchange rate from the day before the system came into force, became the parity rate. Since then, the parity has been modified twice. At the end of 1994, when oil discoveries were made in the country, the parity was increased by $7 \%$, that is, the bottom of the former band became the middle of the new as the exports of oil would imply more US dollar inflows to the country. The second time was on 3 September, 1998, as the result of increasing pressure on the peso triggered by the Asian crisis, and the worsening of the twin deficits (fiscal and current account). On this occasion, the parity was reduced by $9 \%$.

To decrease inflation's inertia, the international convention to set the slope of the parity (the crawling rate) as the difference between the inflation goal and international inflation, was followed. Initially, the slope for the COP was defined as $11 \%$ and it was usually reset at the beginning of each year together with the new macroeconomic program and inflation goal.

The strength of external shocks and exchange rate volatility have to be taken into account when determining the band's width. Historical data to 1994 showed that a width of $\pm 4 \%$ from the central parity would be adequate to absorb external shocks. However, Banco de la Republica chose a width of $\pm 7 \%$ as further developments were expected on the foreign exchange market and loose fiscal policy from the government could not be discarded (Williamson, 1996). 


\section{The data and preliminary analysis}

\subsection{The data: sources and markets}

Currency markets in Colombia encompass spot, next day and forward trades. Over-thecounter (OTC) options are occasionally traded. Inter-bank COP trades value spot from 8:00 a.m. to $13: 00$ p.m. From 14:30 p.m. to $16: 30$ p.m., the convention is that any transaction will be settled on the next day, although this "Next-Day" market tends to be very illiquid. Therefore, the Central Bank only intervened in the spot market to protect the limits of the band. During the period under study, more than $80 \%$ of the overall business was done through the Citiinfo system. The remaining trades were usually executed by telephone.

Citiinfo's information on the Spot market was therefore used. The data set consists of daily Close of Trade (C_close), Maximum Trade (C_max), Minimum Trade (C_min) and Average Trade (C_prom) observations from January 1994 (when the explicit band was set) to June 1998. The information related to the band, that is the upper limit (MaxBd), the central parity (MedBd) and the bottom (MinBd) was also used. Log-returns from the daily average rate of the trades executed through the Citiinfo system (C_AvgRet), the daily change from opening to closing (C_Clop) and the maximal variation during the day (C_MinMax) were computed.

\subsection{Exchange rate general statistics}

In common with the majority of financial return series, the distribution of COP returns has fat tails and a peak at the mean. Skewness (0.612) and excess Kurtosis (27.5) are both significantly different form zero at the $1 \%$ level, the latter confirming the hypothesis of a leptokurtic distribution - see Figure 1. The normality plot (Figure 2) shows in a graphical manner whether returns are normally distributed. If the data are normal, the plot will be linear while other distributions will introduce curvature.

During the period 1994-1998, the nominal exchange rate was closer to the limits of the band ( \pm $7 \%$ from the central parity). Thus, a histogram of the deviations from central parity shows a concentration on the upper side of the band and more observations near the central parity than expected by the currency band models (Figure 3). These predict a $U$ shaped distribution if no intra-marginal intervention is implemented by the Authorities to drive the rate towards the middle of the band.

The excess observations near the parity result from a $7 \%$ revaluation of the Central Parity at the end of 1994 that de-facto, as the rate was hitting the bottom, left the currency in the middle of the new band until mid 1995. The high concentration on the weak side arose from the political crisis between August 1995 and June 1996 (alleged financing of the presidential campaign by the drug cartels) and the realignment expectations during the first quarter of 1998. 


\subsection{Distinct Regime statistics}

Under Currency Bands, possible future exchange rate paths are limited. Thus, even when the Authorities are not defending the limits and the rate is within the band, exchange rate dynamics differ from a free float mechanism. In fact, when the Central Bank's ability to defend the bands is credible, the exchange rate is not only determined by the evolution of the fundamentals, but also by the impact on agents' expectations of the Authorities' resolve to intervene in the boundaries of the band.

Given that agents' expectations may depend on the level of the exchange rate when compared with the central parity and the limits of the band, the volatility of the returns and the proportion of time elapsed is analysed under three regimes. These are defined by dividing the band into quarters. Regimes 1 and 3 correspond to the upper and lower quarter respectively and regime 2 includes both central quarters. Formally:

Regime1: $\quad[\operatorname{MaxBd}(\mathrm{t}), \operatorname{MaxBd}(\mathrm{t})-(\operatorname{MaxBd}(\mathrm{t})-\operatorname{MinBd}(\mathrm{t})) / 4]$

Regime2: $\quad](\operatorname{MaxBd}(\mathrm{t})-(\operatorname{MaxBd}(\mathrm{t})-\operatorname{MinBd}(\mathrm{t})) / 4, \operatorname{MinBd}+(\operatorname{MaxBd}(\mathrm{t})-\operatorname{MinBd}(\mathrm{t}) / 4))[$

Regime3: $\quad[\operatorname{MinBd}(\mathrm{t})+(\operatorname{MaxBd}(\mathrm{t})-\operatorname{MinBd}(\mathrm{t})) / 4), \operatorname{MinBd}(\mathrm{t})]$

Figure 4 presents the evolution of the Colombian Peso in those regimes from January 24, 1994 to June 17,1998 . The sample period can be approximately divided into 10 sub-intervals in which the rate is inside one of these regimes.

Some summary statistics for these sub-intervals are presented in Table 1, and a number of features are worth noting. From July 1996 onwards, the exchange rate tends to remain in regimes 1 and 3 . In general terms, the annualised volatility for the whole sample, $5.2 \%$ is low if compared with actively traded currencies such as the Deutsche mark or the Japanese yen, which have annualised volatility around 12 or $14 \%{ }^{\mathrm{vi}}$. From Table 1, a gradual structural increase in volatility seems apparent, as the market was developing during the period ${ }^{\text {vii }}$.

Note that in general, COP crossed or "touched" temporarily the second regime for a few days with very high volatility. During the months of August and September 1997, COP depreciated more than $12 \%$ and the major part of the move took place in 17 days that accounted for a volatility of $15.7 \%$.

The revaluation of the Central Parity in mid December 1994, was followed by a sharp depreciation fuelled by accusations of illegal financing of the presidential campaign (from August 1995 to July 1996). Consequently, the sample from the end of July 1996 to June 1998 is used for analysis in the rest of this section. During this period, COP has remained only $20 \%$ of the days in regime 2 , and $40 \%$ in each of the two other regimes. 
Table 2 presents the total length of time that the COP spends in each regime, and also the time-weighted volatilities for each regime. As expected, the time-weighted volatility is higher when the exchange rate is closer to the central parity. Volatility is generally much higher for regime 2 than for regimes 1 or 3 .

\subsection{Summary Statistics}

Literature closely related to the Efficient Market Hypothesis (EMH) states that the natural logarithm of the exchange rate should follow a random walk, i.e. should follow a martingale:

$$
\mathrm{X}(\mathrm{t})=\mathrm{X}(\mathrm{t}-1)+\mathrm{u}(\mathrm{t})
$$

Where $X(t)$ represents the natural logarithm of the exchange rate and $u(t)$ is a white noise random variable $(\mathrm{u}(\mathrm{t}) \sim \mathrm{iid}(0,1))$. Some summary statistics for the data, as defined in Section 3.1, are given in Table 3.

The Dickey Fuller test shows unsurprisingly that there is a unit root in the exchange rate series (C_Prom). A daily trend of $0.05 \%$ seems to be present in the data for the returns (C_PromRet). This could result from the drift imposed by the authorities implicitly in the crawling rate of the band (11\%,13\%,15\% and 13\% for 1994, 1995 and 1996, 1997 and 1998 respectively) as the annualised trend arising from the data for the whole period is equivalent to $12.8 \%$. The series of returns computed using the opening and closing price of the day (C_Clop) confirms the result with a smaller trend of $0.025 \%$. Table 4 presents autocorrelation coefficients and a Ljung-Box statistic for average returns (C_AvgRet), the squared of average returns (C_AvgRet^2), the open-close returns, and the daily range (C_MinMax).

Table 4 shows that the serial correlation of returns is not very strong, but the autocorrelation coefficients of the squared returns statistically differ from zero at the $5 \%$ level for lags 1, 2, 8, 9 and 10. The autocorrelation function for the daily range of the exchange rate (C_MinMax), another measure of volatility, confirms this result and shows strong evidence of volatility clustering, a feature which is also demonstrated by Figure 5 . The latter also seems to suggest a gradual increase in volatility over the sample period.

\subsection{Non-linear Effects}

The findings from the previous section suggest that the disturbances are not homoscedastic and that the autocorrelation function for the daily range proposes that it could depend on the previous' day range.

A test for autoregressive conditional heteroscedasticity (ARCH) was carried on two sets of data: logarithmic daily returns calculated with the average Citiinfo rate (C_PromRet) and the logarithmic returns computed from the difference between the opening and closing rate for each day (C_Clop). Results are shown in Table 4 and in both cases, although only the first lag is significant, the test statistic rejects the hypothesis of no $\mathrm{ARCH}$ effects in the data, at the $1 \%$ 
level. However, much care must be taken in interpretation of these results, as it is plausible that instead of being evidence of short-term memory, the observed non-linearity could be evidence of some sort of stochastic switching process. The second assertion seems to be supported by the results (see section 5.2) for the dynamics of the volatility of the returns and from solutions to theoretical models of exchange rates under currency bands, which include a non-linear factor in order to capture the effective complexity of the system (Krugman, 1991 and Froot and Obstfeld,1989).

In summary, COP presents the statistical properties expected from a financial time series and in particular from currency bands theory. Volatility of returns is higher near the central parity and the exchange rate tends to stay close to the limits of the band. Clearly the distribution of returns is leptokurtic and the COP is non-stationary. In the following section, an application of stochastic differential equations is proposed to model the behaviour shown by these stylised features, of the COP.

\section{The Colombian Peso (COP) model}

A model of the Colombian Peso during the period under study must account for the stochastic features of the exchange rate as well as the effective complexity that arises from the regularities created by the band's properties, namely its crawling rate, higher volatility near the central parity and its width. These features are modelled through a drift component, a volatilityswitching factor related to the position of the exchange rate within the bands and a pair of reflecting barriers respectively. The additional characteristic of this model is that a central parity reversion factor is included in the stochastic differential equation (SDE). This modification responds to the fact that if the band is credible and the currency is trading towards the limits, expectations of future intervention result in a correction of the trend by the agents. Moreover, mean reversion could respond to interventions by the Central Bank to push the currency towards the Central Parity. It should be noted that intra-marginal intervention could be used by the Authorities to reduce intra-day or daily volatility or to drive the rate towards the mid-point of the band. In the model presented, the former is embedded included in the diffusion coefficients inputted in the model.

The resulting specification of the model is:

$d X(t)=A[X(t), \operatorname{Medbd}(t), t] \cdot d t+B[X(t), t] \cdot d B(t)$

where

$A[X(t), t]=\mathbf{a} \cdot X(t)+\mathbf{c} \cdot[X(t)-\operatorname{MedBd}(t)]$

$$
B[X(t), t]=\begin{array}{ll}
\text { b1. } X(t) & \text { if } A[X(t), t] \cdot d t+B[X(t), t] \cdot d B(t) \subset \text { Regime } 1 \\
\text { b2. } X(t) & \text { if } A[X(t), t] \cdot d t+B[X(t), t] \cdot d B(t) \subset \text { Regime 2 } \\
\text { b3. } X(t) & \text { if } A[X(t), t] \cdot d t+B[X(t), t] \cdot d B(t) \subset \text { Regime 3 }
\end{array}
$$


with the following constraints on the limits of the band and behaviour within:

$$
\begin{gathered}
\operatorname{MaxBd}(T) \Rightarrow X(0)+\int_{t=0}^{T} A[X(t), t] d t+\int_{t=0}^{T} B[X(t), t] d B(t) \succ \operatorname{Maxbd}(T) \\
X(T)=\quad X(0)+\int_{t=0}^{T} A[X(t), t] d t+\int_{t=0}^{T} B[X(t), t] d B(t) \\
\operatorname{MinBd}(T)) \Rightarrow X(0)+\int_{t=0}^{T} A[X(t), t] d t+\int_{t=0}^{T} B[X(t), t] d B(t) \prec \operatorname{Minb}(T)
\end{gathered}
$$

where $A[X(t), t]$ includes the drift, $\{\mathbf{a} . X(t)\}$ and the Central Parity Reversion factor, $\{\mathbf{c} .[X(t)-$ $\operatorname{MedBd}(\mathrm{t})]\}$. The terms a (drift) and $\mathbf{c}$ (reversion) are the unknown coefficients that will be estimated. $B[X(t), t]$ is a diffusion function and $\mathbf{d B}(t)$ is the increment of a Brownian motion process that represents the innovation term in the SDE. The diffusion function consists of 3 independent diffusion coefficients (b1, b2 and b3) linked to a corresponding regime of the exchange rate. The definition of regimes presented in Section 3.3 will be retained for the simulation runs.

Finally, constraints are imposed to the dynamics of the exchange rate in the limits of the band to preclude the path followed by $X(t)$, from equation 1 above from crossing above $\operatorname{Maxbd}(T)$ or below Minbd(T) in $T$. In practice, Central Bank intervention will ensure that the rate will not surpass these limits.

By setting $\mathbf{c}=0$, we obtain a general Geometric Brownian Motion process with drift, reflecting barriers and regime switching volatility. By additionally setting $\mathbf{b} \mathbf{1}=\mathbf{b} \mathbf{2}=\mathbf{b} \mathbf{3}=\mathbf{b}$ we would obtain $\mathbf{a}$ GBM process with drift and reflecting barriers.

\section{Estimation Results and Conclusions}

\subsection{Simulation and Estimation}

Figure 6 shows the loss function for a combination of parameters. The drift is bounded between 10 and $25 \%$ and the reversion between 0 and 1 . The graph was constructed using a cubic interpolation technique. Clearly, the optimal reversion coefficient is very close to zero.

Following Section 3.3, the set of historical moments for each regime, $H^{\prime}$, and the standard deviation of the exchange rate were calculated for the period commencing July 1996 and ending in June 1998. This information was used as the input for the optimisation. The grid search algorithm finds that a drift coefficient of $14.65 \%$, higher than the average crawling rate implicit in the band's design, and a central parity reversion $(C=0.0002206)$, minimises the discrepancy between the observed and the generated moments. 
The optimal drift was slightly higher than that of the crawling rate of the band. As the inflation target for both years was approximately attained and the crawling rate is computed as the expected inflation differential between Colombia and the rest of the world, it would not seem that the expected rate of devaluation implicit in the Authorities' objective was too low. The higher drift rate could result form a worsening of the twin deficits, as a consequence of the fall of commodities prices and an increase in public expenditure, combined with local political uncertainty and external unrest in the financial markets. Another complementary factor that could generate a higher drift is asymmetry in the regulation related to net foreign currency holdings that forbids financial institutions to maintain a negative net position for more than one day.

In relation to the parity reversion, two possibly complementary hypotheses can be formulated. Either Banco de la República does intervene intra-marginally or, as currency bands theory asserts, intervention in the limits would generate appreciation expectations when the rate is near the top of the band and depreciation expectations near the bottom. However, as the parity reversion is around 0.0002 for a width of $\pm 7 \%$, the maximum daily reversion is $0.0015 \%$, only $6.52 \%$ of the daily average change. The intervention, if performed by the Central Bank, does not seem to be directed to push the rate towards the parity. The latter is in line with the statements given by the Central Bank in 1998 in the sense that the intra-marginal intervention, if any, is directed to minimise the volatility of the exchange rate and not to affect any prevailing tendencies. Also, the band's credibility seems to be low during the period under study. Cardenas and Bernal (1997) showed that interest rate volatility is higher than that expected in a credible exchange rate band and that both interest rate and exchange rate volatilities are higher than those governed by the fundamentals identified in their research. The band's realignment in September 1998 and the further elimination of the band in September 1999 seem to support that claim.

The average discrepancies for each regime are given in Table 6. If the moments for the intraday mean and standard deviation are included the same set of parameters are found and the loss function, $\mu_{\Omega}$, is equal to $0.53 \%$. Deviations from these moments are $1.6 \%$ and $0.33 \%$ in absolute terms.

Comparing Figures 7 and 8 , the actual COP histogram is very similar to the one generated by the simulated samples.

Econometric tests were conducted on the returns from the simulated data generated with the optimal parameters for Jul96-Jun98. The temporal dynamics of the simulated series was first tested for a unit root by applying a Dickey Fuller test. As expected, the simulated exchange rates have a unit root while the simulated returns are stationary - see Table 7 . 
Table 7 also shows general statistics on the historical and simulated returns. The process modelled as a Geometric Brownian motion with drift, reflecting barriers regime varying volatility and parity reversion $(G B M+R B+R V+P R$ ) captures adequately the mean, variance and kurtosis of the historical data. However, skewness still uncaptured. As with the historical series, linear dependence in the squared returns and hence autoregressive conditional heteroscedasticity is present in the series.

Although the set of moments were calculated by reference to the time spent by the rate in each regime, the series generated seem to account for most of the statistical properties of the data.

\subsection{Conclusions}

The goal of our study was to capture, in a simulated model, the stylised features of the Colombian peso (COP) exchange rate system. For this purpose, a three-regime volatilityswitching stochastic model with parity reversion and drift was fitted to the data by minimising a loss function using a grid search algorithm. The statistical characteristics of the simulated series are similar to the statistical properties of the returns from the historical sample. In fact, they account for the kurtosis and the non-linear dependence of the exchange rate series. Although the loss function minimises the difference between the average length of time spent by the simulation and the actual data in each regime, the resulting moments of the density function for the simulated returns fit adequately most the characteristics of the sample returns data.

The model that we propose could serve as a useful tool for a Central Bank seeking to measure the band's credibility, intervention effectiveness and crawling rate verification. It could also be used to price options on exchange rates under currency bands using the Feynman-Kac representation. A natural extension to our model would be an attempt to encompass realignment expectations. These rare events could be modelled using a Poisson distribution. Volatility could also be modelled as a complementary stochastic differential equation with inverted parity reversion so that volatility increases as the rate is closer to the central parity. 


\section{References}

Banco de la República (1997). Régimen de cambios internacionales de Colombia 1997, Banco de la República, Bogotá, Colombia.

Bandera, V.N. and Lucken, J.A. (1985) Simulation of a Debtor Country: The Example of Colombia Journal of Policy Modelling 7(3).

Bertola G. and Caballero R. (1992). Sustainable intervention policies and exchange rate dynamics in Exchange Rate Targets and Currency Bands, Edited by Paul Krugman and Marcus Miller, Cambridge University Press.

Buiter W. and Grilli V. (1992). Anoumalous speculative attacks on fixed exchange rate regimes:possible resolutions of the 'gold standard paradox', in Exchange Rate Targets and Currency Bands, Edited by Paul Krugman and Marcus Miller, Cambridge University Press.

Canterbery, E.R. and Boorman, J.T. (1970) The Crawling Peg and Exchange Stability Canadian Journal of Economics 3(2), 291-299

Cárdenas M. and Bernal R. (1997). La tasa de cambio en Colombia, Bogotá, Colombia.

Carrasquilla A. (1997a). "An Exchange Rate Band in Times of Turbulence: Colombia 19911996", Borradores Semanales de Economía, Banco de la República, January 1997, Bogotá, Colombia.

Carrasquilla A. (1997b). "Monetary Policy Transmission: the Colombian Case", Bank of International Settlement.

Cumby, R.E. and Van Wijnbergen (1989) Financial Policy and Speculative Runs with a Crawling Peg: Argentina 1979-1981 Journal of International Economics 27, 111-127.

Edwards, S. (1986) Commodity Export Prices and the Real Exchange Rate in Developing Countries: Coffee in Colombia in Edwards, S. and Ahamed, L. (eds) Economic Adjustment and Exchange Rates in Developing Countries, University of Chicago Press, Chicago, IL.

Edwards, S. (1985) Money, the Rate of Devaluation, and Interest Rates in a Semiopen Economy: Colombia, 1968-82 Journal of Money, Credit and Banking 17(1).

Flood R.P. and Garber P. (1992). The linkage between speculative attack and target zone models of exchange rate: some extended results in Exchange Rate Targets and Currency Bands, Edited by Paul Krugman and Marcus Miller, Cambridge University Press. 
Froot K.A. and Obstfeld (1992). Stochastic process switching: some simple solutions in Exchange Rate Targets and Currency Bands, Edited by Paul Krugman and Marcus Miller, Cambridge University Press.

Kamas, L. (1985) External Disturbances and the Independence of Monetary Policy under the Crawling Peg in Colombia Journal of International Economics 19, 313-327,

Kloeden P.E., Platen E. and Schurz H. (1997). Numerical solution of SDE through computer experiments, Springer-Verlag Berlin Heidelberg, Germany.

Krugman P (1991), Target zones and exchange rate dynamics. Quaterly Journal of Economics.

Krugman P. (1992). Exchange rates in a currency band: a sketch of the new approach, in Exchange Rate Targets and Currency Bands, Edited by Paul Krugman and Marcus Miller, Cambridge University Press.

Krugman P. (1997). Crisis de la moneda, Editorial Norma S.A., Bogotá, Colombia

Krugman P. and Rotemberg J. (1990). Target zones with limited reserves, NBER working paper No. 3418.

Krugman P. and Rotemberg J. (1992). Speculative attacks on target zones, in Exchange Rate Targets and Currency Bands, Edited by Paul Krugman and Marcus Miller, Cambridge University Press.

Levin, J.H. (1975) Monetary Policy and the Crawling Peg Economic Journal 85, 20-32.

Meltzer, A.H. (1996) The Choice of the Monetary Regime in Langoni, Ferer and Ronci (eds.) The Quest for Monetary Stability

Reennhack and Modino (1988) Capital Mobility and Monetary Policy in Colombia IMF Working Paper 88/77 (August)

Smith G. and Spencer M. (1992). Estimation and testing in models of exchange rate target zones and process switching in Exchange Rate Targets and Currency Bands, Edited by Paul Krugman and Marcus Miller, Cambridge University Press. 
Urrutia, M. (1981) in Williamson (ed.) Exchange Rate Rules: The Theory, Performance and Prospects of the Crawling Peg, St. Martin's Press, New York.

Williamson J. (1996) The crawling band as an exchange rate regime. Lessons from Chile, Colombia and Israel. Washington: Institute for International Economics.

Williamson, J. (1987) Exchange Rate Management: The Role of Target Zones American Economic Review 77(2), 200-204

Williamson, J. (1986) Target Zones and the Management of the Dollar Brookings Papers on Economic Activity 17(1), 165-174 


\section{Appendix: Approximations and the Method-of-Simulated-Moments (MSM)}

\section{Numerical Approximations: Euler Scheme}

A numerical approximation is used to estimate the solution to the SDE presented above. The scheme applied for this purpose is now presented. Following Kloeden, Platen and Schurz (1997), if we consider an Ito process $X=\left\{X(t), t_{0}<=t<=T\right\}$ that satisfies the stochastic differential equation:

$$
d X(t)=A[X(t), t] \cdot d t+B[X(t), t] \cdot d B(t)
$$

Where the functions $\mathbf{A}[\mathbf{X}(\mathbf{t}), t]$ and $\mathbf{B}[\mathbf{X}(\mathbf{t}), \mathrm{t}]$ are the drift and diffusion coefficients and with the initial value of $X$ known

$$
X(0)=X_{0}
$$

For a given discretization of the time period $[0, T]$ into $n$ intervals of equal length $k=T / n$, an Euler approximation is a continuous time stochastic process $Y=\left\{Y(t), t_{0}<=t<=T\right\}$ satisfying the difference equation:

$$
Y_{n+1}-Y_{n}=A\left(\tau_{n}, Y_{n}\right)\left(\tau_{n+1}-t_{n}\right)+B\left(\tau_{n}, Y_{n}\right)\left(W \tau_{n+1}-W \tau_{n}\right)
$$

For $\mathrm{n}=0,1,2, \ldots, \mathrm{N}-1$ and with

$$
Y_{n}=X_{0}
$$

The sequence of values for the Euler approximation can be computed in a similar way to those of the deterministic case. However, for the calculations, Brownian motion increments $\Delta \mathrm{W}=$ $\left(\mathrm{W} t_{n+1}-\mathrm{W} t_{n}\right)$ have to be generated. These have a normal distribution with mean zero and standard deviation equal to one. The Polar-Marsaglia generator was used for this purpose.

\section{Grid search algorithm by the Method-of-Simulated-Moments (MSM)}

Smith and Spencer (1992) estimate and test exchange target zones for the Deutsche MarkLira cross spot rate (DEM/ITL) using the method-of-simulated-moments. In the MSM procedure, the estimation of the parameters is implemented by matching the sample moments of the historical data with the moments of the simulated series by minimising a loss function of the difference between the two.

The main argument to support the use of this technique is that the unobservability of the fundamentals precludes any direct estimation of a non-linear regression model linking the exchange rate to the fundamentals. It also precludes any maximum likelihood estimation or analytical calculation of the moments of the exchange rate. Moreover, simulation estimation must be used, as the analytical expressions for the moments used in the estimation may not be known.

Stochastic solutions are evaluated by their sampling characteristics. Therefore, the objective of optimisation in this context is to obtain a set of parameters (drift and/or reversion coefficient) that generate a sample of paths that will have similar statistical properties to the financial series. In this framework, we will consider an adequate solution to be a combination of 
parameters that closely replicates the proportion of days spent by the exchange rate in each regime. In order to accomplish such a goal, we define a loss function, $\Omega$, that adds the absolute deviation from the target proportions under each regime for $\boldsymbol{M}$ runs of the model and $\boldsymbol{T}$ time steps. In the procedure, the $\boldsymbol{\Omega}$ function is computed $\boldsymbol{S}$ times for each set of parameters. Then, its mean is calculated and recursively the algorithm tries to minimise the mean with a set of constraints, particularly in the values that the parameters can take as well as the deviation from each regime. Formally the process is as follows.

Define the regime function $Z[$.] as:

$$
\begin{aligned}
& 1 \text { if } X_{m, t} \subset \text { Regime i } \\
& Z_{m, t}^{i}= \\
& 0 \text { otherwise }
\end{aligned}
$$

Where $\boldsymbol{m}$ refers to the path, $\boldsymbol{i}$ to the regime and $\boldsymbol{t}$ to the time step for a given path. $\boldsymbol{X}_{\boldsymbol{m}, \boldsymbol{t}}$ is the value of the exchange rate for a path $\boldsymbol{m}$ at $\boldsymbol{t}$.

The function $\Omega_{\mathbf{a}, \mathbf{c}}$ is then computed for each set of parameters $\mathbf{a}$ and $\mathbf{c}, \boldsymbol{S}$ times as:

$$
\Omega_{a, c}=\sum_{\mathrm{i}=1}^{\mathrm{I}}\left[\frac{\left(\sum_{\mathrm{m}=1}^{\mathrm{M}} \sum_{\mathrm{t}=1}^{\mathrm{T}} \mathrm{Z}_{t, m}^{i}\right)}{(T \times M)}-H^{i}\right]^{2}
$$

Where $\boldsymbol{H}^{\boldsymbol{}}$ is the historical proportion of days that the COP spent in the regime $\boldsymbol{i}$ in a given period, $\boldsymbol{T}$ is the number of time steps and $\boldsymbol{M}$ is the number of paths.

The optimisation can be then written as a minimisation of the mean of the loss function $\Omega_{\mathbf{a}, \mathbf{c}}$ subject to constraints on the absolute difference between Z[.] and $H^{\prime}$.

Minimise

$$
\mu_{\Omega_{a, c}}=\frac{\sum_{s=1}^{S} \Omega_{a, c}^{s}}{S}
$$

Subject to

1. $\left|Z[\cdot]-H^{i}\right|<\pi$

2. $\lambda_{1}<\mathrm{C}<\lambda_{2}$,

3. $\delta_{1}<\mathrm{a}<\delta_{2}$

Where $\mu_{\Omega \mathrm{a}, \mathrm{c}}$ is the mean of the loss function $\Omega_{\mathrm{a}, \mathrm{c}}, Z^{\prime} /(T x M)$ is the proportion of time steps that the simulated rate spends in the regime $\boldsymbol{i}$ and $\boldsymbol{H}^{\boldsymbol{i}}$ is the historical percentage of days the rate 
was in regime $i$ during a period under study. $\mathbf{a}$ is the drift and $\mathbf{c}$ is the parity reversion coefficient. $\lambda_{1}, \lambda_{2}, \pi, \delta_{1}$ and $\delta_{2}$ are predetermined coefficients.

Note that the volatilities used for the diffusion term in the stochastic differential equation are given as computed from historical data. Constraints 2 and 3 are used to reduce the estimation time and to ensure that the drift term is "close" to the crawling rate of the band and that the reversion coefficient is positive. It is clear that $c$ must be between 0 and 1 and it can be expected to be small as a coefficient: $\mathbf{c}=1$ would imply that the rate is permanently close to the central parity, that is, similar to a crawling peg mechanism. It is important to note that for each run, the level of the exchange rate is initialised randomly between the bands and the estimation of the loss function for each combination of parameters to be tested involves at least 3000 runs $(\mathbf{S}=3000)$. Any bias that could arise from the selection of an initial value is therefore eliminated ${ }^{\text {viii }}$. 
Figure 1: COP Returns Histogram

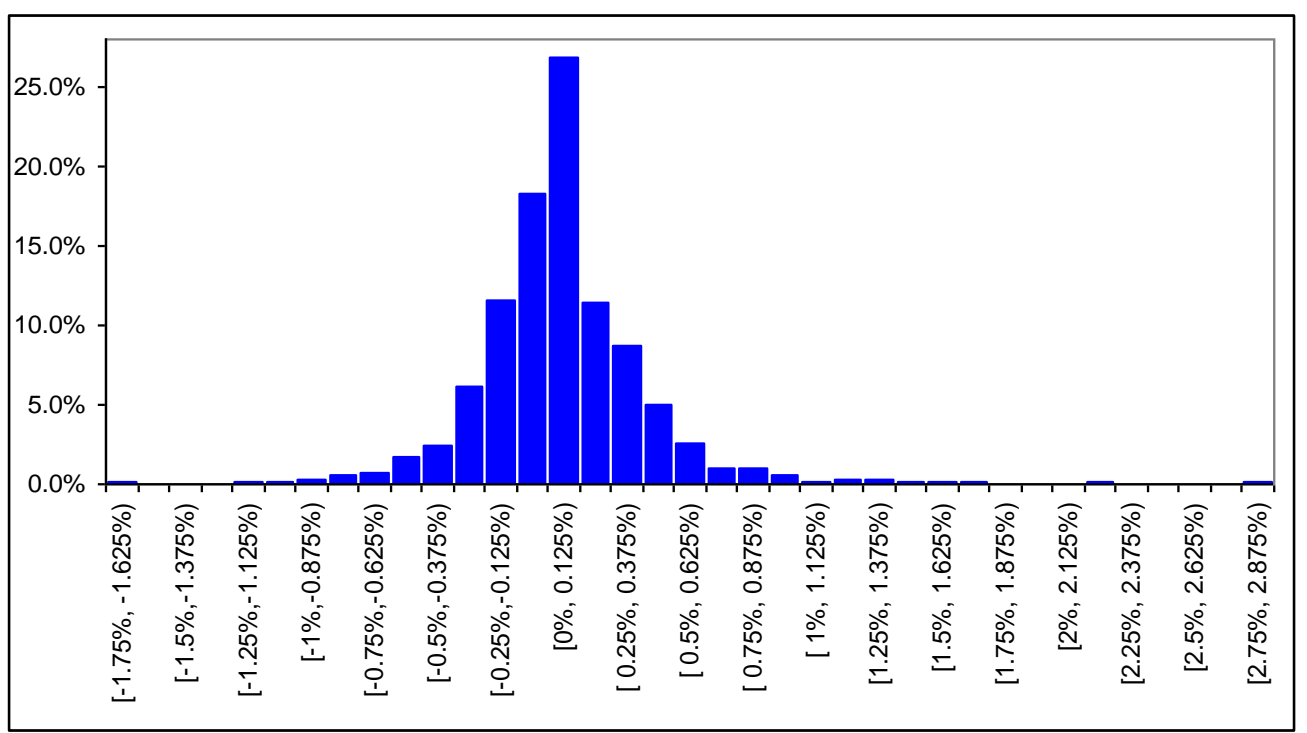

Figure 2: Normality plot for COP returns

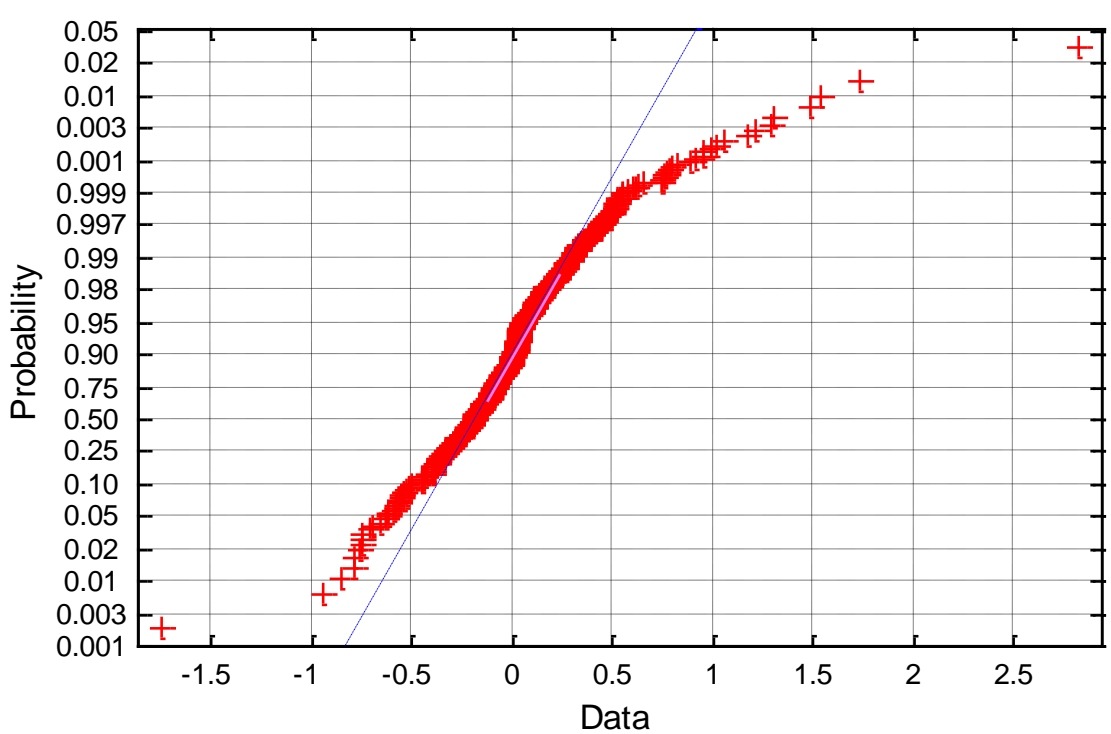

Figure 3: Histogram for COP deviations from Central parity

(Jan. 241994 to June 17 1998)

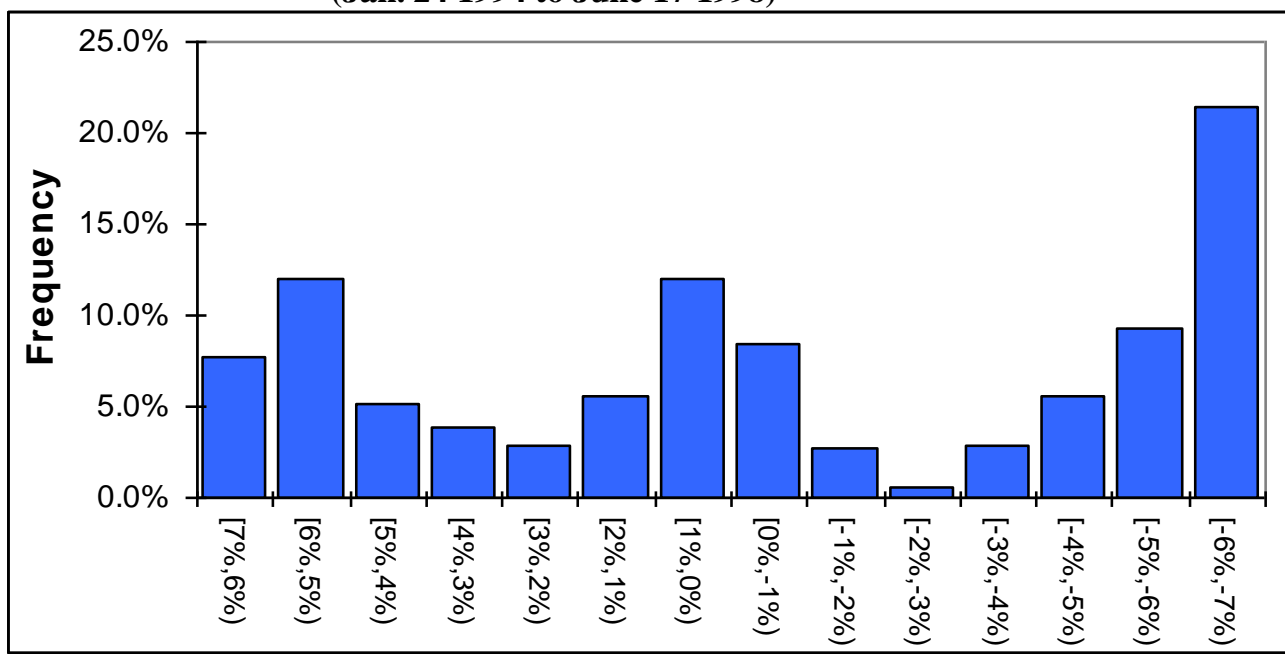


Figure 4: COP and Explicit Bands

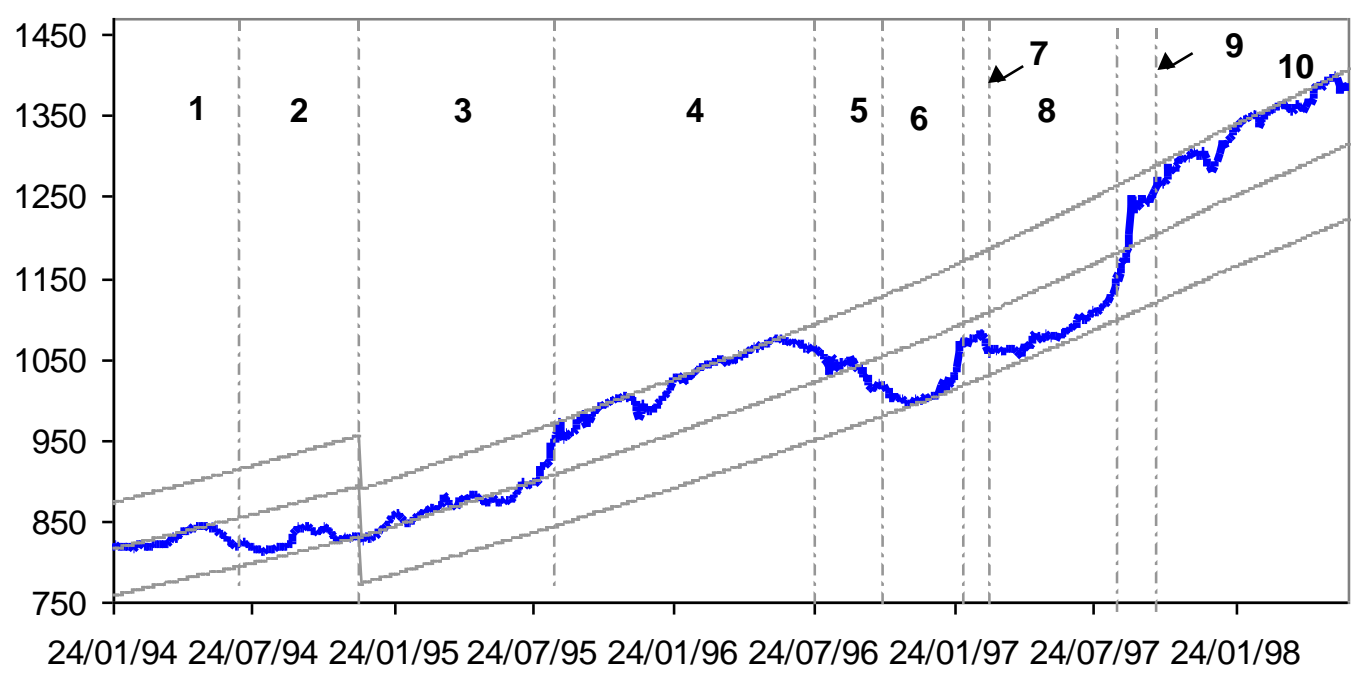

Table 1: Annual volatility and participation by regime

\begin{tabular}{|l|c|c|c|c|}
\hline Period & Ann. Volatility & Days & Regime & $\%$ time \\
\hline 1:24/01/94 - 26/06/94 & $2.7 \%$ & 104 & 2 & $9.7 \%$ \\
2: 27/06/94 - 09/12/94 & $3.0 \%$ & 113 & 3 & $10.6 \%$ \\
3: $12 / 12 / 94-15 / 08 / 95$ & $4.3 \%$ & 164 & 2 & $15.3 \%$ \\
4: $16 / 08 / 95-26 / 07 / 96$ & $5.3 \%$ & 231 & 1 & $21.6 \%$ \\
5: 27/07/96 - 07/10/96 & $6.1 \%$ & 49 & 2 & $4.6 \%$ \\
$6: 08 / 10 / 96-28 / 01 / 97$ & $6.0 \%$ & 73 & 3 & $6.8 \%$ \\
7: 29/01/97 - 04/03/97 & $7.8 \%$ & 25 & 2 & $2.3 \%$ \\
8: 05/03/97 - 20/08/97 & $4.1 \%$ & 111 & 3 & $10.4 \%$ \\
9: $21 / 08 / 97-12 / 09 / 97$ & $15.7 \%$ & 17 & 2 & $1.6 \%$ \\
10: $15 / 09 / 97-17 / 06 / 98$ & $5.5 \%$ & 183 & 1 & $17.1 \%$ \\
All Sample & $5.2 \%$ & 1070 & & $100.0 \%$ \\
\hline
\end{tabular}

Table 2: Regime Total Duration and Weighted Volatility by Regime

\begin{tabular}{|c|c|c|c|}
\hline Regime & No. Days & $\%$ time & Weighted Volatility \\
\hline 1.0 & 183 & $40 \%$ & $5.46 \%$ \\
2.0 & 91 & $20 \%$ & $8.37 \%$ \\
3.0 & 184 & $40 \%$ & $4.82 \%$ \\
All & 458 & $100 \%$ & $6.3 \%$ \\
\hline
\end{tabular}

Table 3: General statistics for COP and COP Returns

\begin{tabular}{|lcccccc|}
\hline Statistics & Mean & Variance & Skew. & E. Kurtosis & DF & ARCH(5) Test \\
\hline C_Prom & 1021.253 & 29036.7 & 0.666 & -0.494 & 1.777 & - \\
[Ho: stat =0] & {$[0.000]$} & & {$[0.000]$} & 0.001 & & \\
\hline C_PromRet & 0.050 & 0.134 & 0.612 & 27.535 & -30.900 & 253.6 \\
[Ho: stat $=0]$ & {$[0.000]$} & & 0.000 & {$[0.000]$} & & \\
\hline C_Clop & 0.024 & 0.094 & 0.737 & 6.626 & -30.263 & 325.1 \\
[Ho: stat $=0]$ & 0.012 & & {$[0.000]$} & {$[0.000]$} & & \\
\hline C_MinMax & 0.371 & 0.118 & 3.541 & 23.028 & - & - \\
[Ho: stat =0] & {$[0.000]$} & & {$[0.000]$} & {$[0.000]$} & & \\
\hline
\end{tabular}

Notes: [.] denotes marginal significance levels, DF and ARCH are the Dickey Fuller unit root and Engle's LM test for $\mathrm{ARCH}$ respectively. The $5 \%$ critical value for the DF test is -2.86 , while the ARCH test asymptotically follows a $\chi^{2}$ distribution with 5 degrees of freedom. 
Table 4: Autocorrelation functions

\begin{tabular}{|c|c|c|c|c|}
\hline Lag & C_AvgRet & C_AvgRet ${ }^{\wedge} 2$ & C_Clop & C_MinMax \\
\hline 0 & 1 & 1 & 1 & 1 \\
1 & 0.055 & 0.432 & 0.075 & 0.620 \\
2 & -0.047 & 0.076 & -0.062 & 0.403 \\
3 & -0.009 & 0.032 & -0.013 & 0.366 \\
4 & 0.053 & 0.051 & 0.057 & 0.341 \\
5 & 0.033 & 0.027 & 0.059 & 0.328 \\
6 & 0.056 & 0.021 & 0.005 & 0.257 \\
7 & 0.031 & 0.016 & 0.096 & 0.202 \\
8 & -0.014 & 0.061 & 0.066 & 0.218 \\
9 & 0.007 & 0.075 & -0.003 & 0.202 \\
10 & 0.104 & 0.060 & 0.023 & 0.169 \\
\hline Q(10)-Stats & 26.301 & 225.369 & 32.782 & 1214.6 \\
Sig. Lev. & 0.003 & 0.000 & 0.000 & 0.000 \\
\hline
\end{tabular}

Notes: $Q(10)$ is a Ljung-Box test for autocorrelation with 10 lags; the test statistic is asymptotically distributed as a $\chi^{2}(10)$ under the null.

Figure 5: COP Daily Range

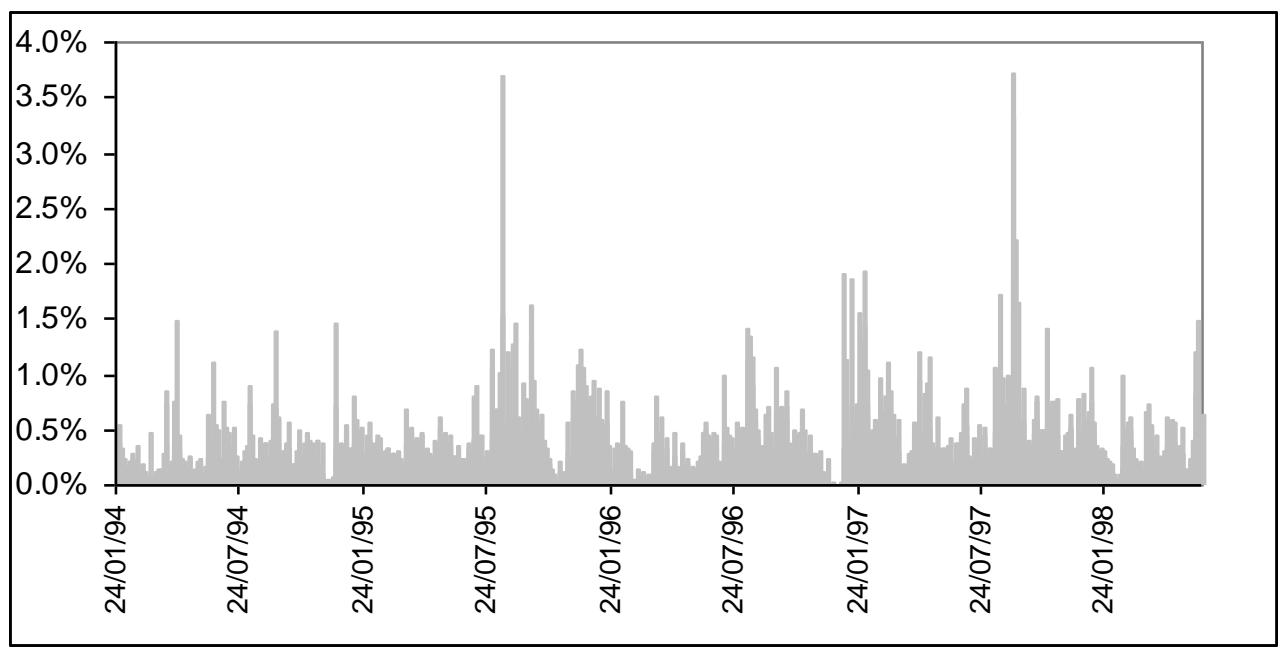

Figure 6: Loss function landscape.

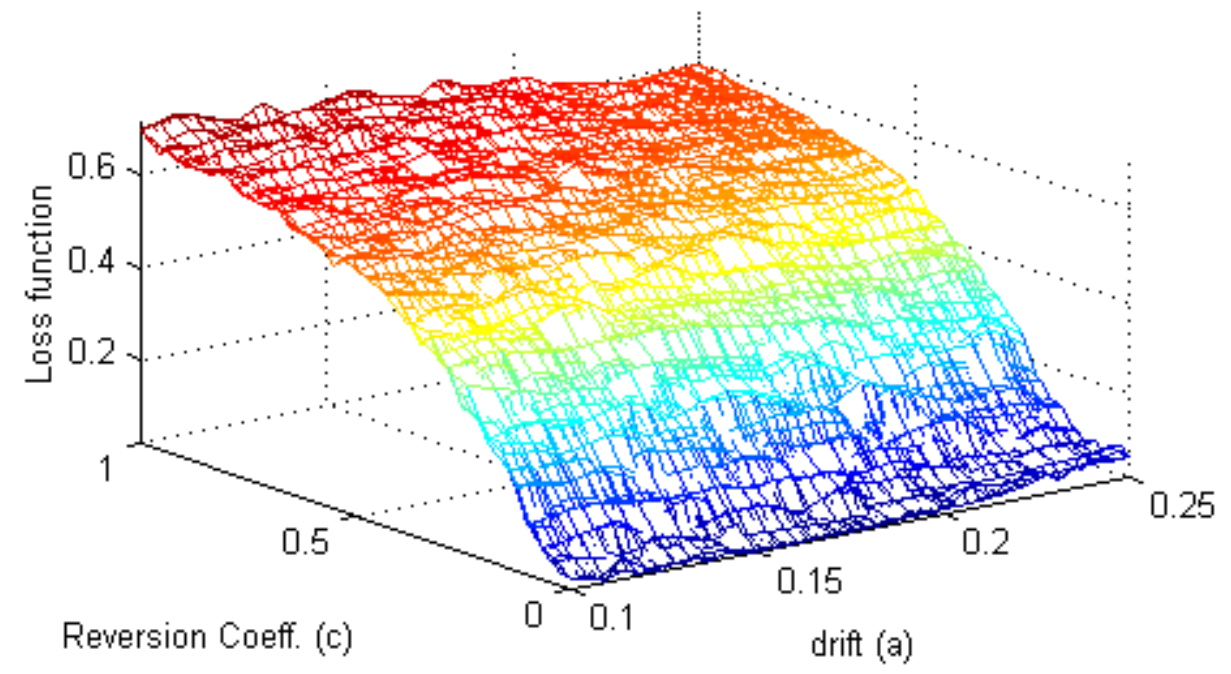


Table 5: Grid Search Results Jul96-Jun98

\begin{tabular}{|c|c|c|c|}
\hline Model & $\mu_{\Omega}$ & c & $\mathbf{a}$ \\
\hline GBM+RB+RV+PR & $0.56 \%$ & 0.0002206 & $14.65 \%$ \\
\hline
\end{tabular}

Table 6: Discrepancies by Regime

\begin{tabular}{|c|c|c|c|}
\hline Moments Set from & \multicolumn{3}{|c|}{ Jul96 - Jun98 } \\
\hline Model & Reg1 & Reg2 & Reg3 \\
\hline GBM+RB+RV+PR & $2.0 \%$ & $5.8 \%$ & $3.8 \%$ \\
\hline
\end{tabular}

Figure 7: Actual COP Deviations Histogram

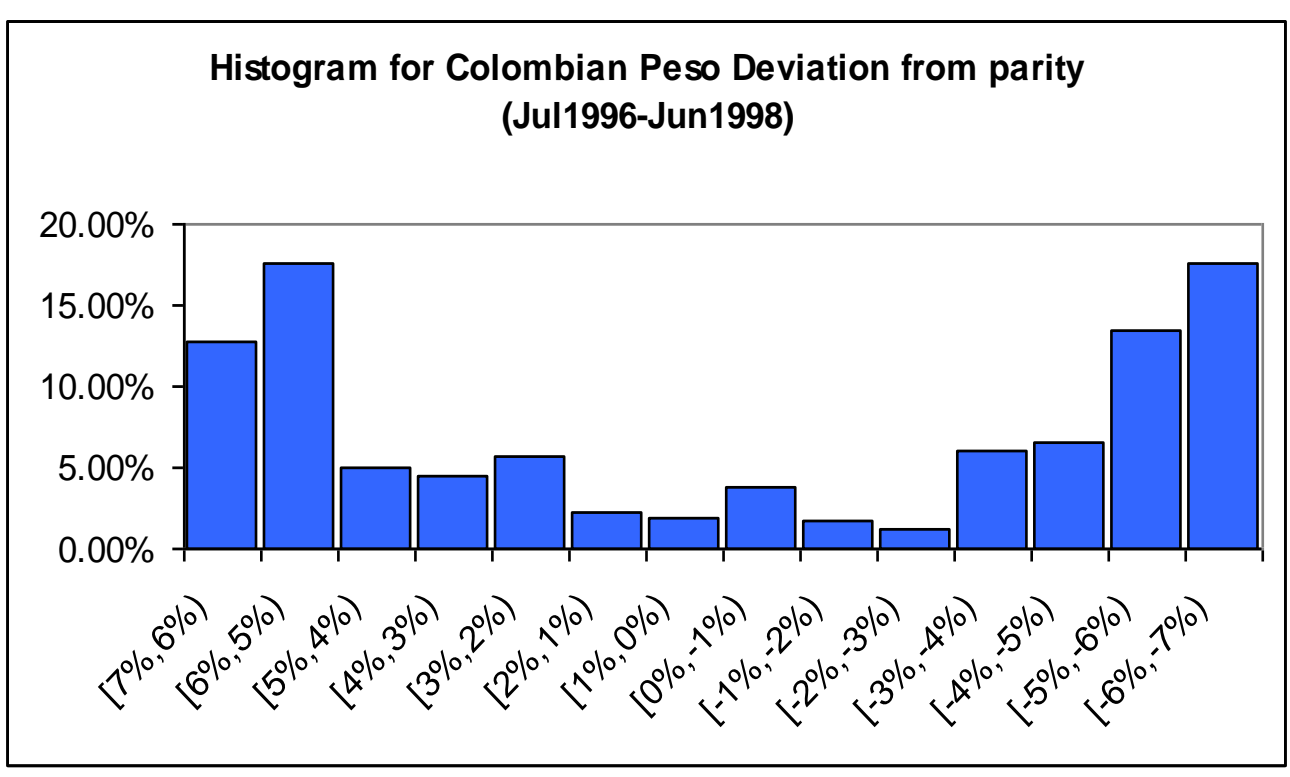

Figure 8: Simulated Deviations Histogram

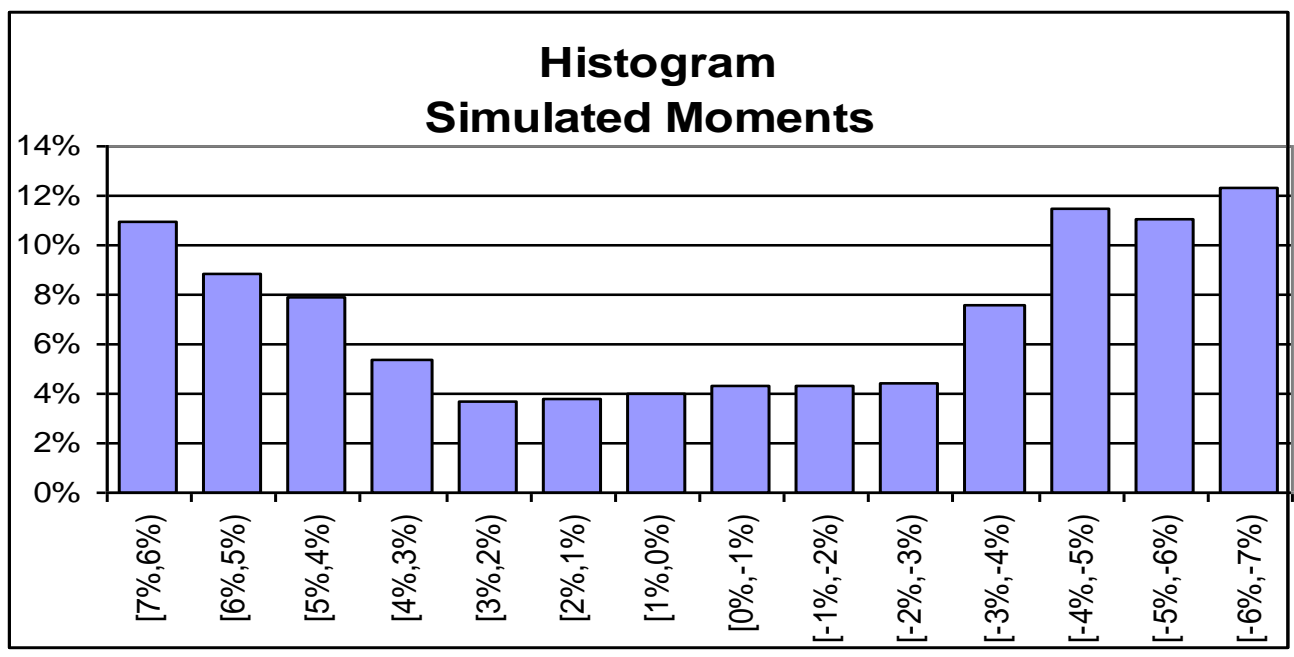


Table 7: Statistics on historical and simulated return

\begin{tabular}{|lccccccc|}
\hline Sample & Mean & Var & Skew & Kurt & $\begin{array}{c}\text { L-B Q(10) } \\
\text { Returns Sqrd }\end{array}$ & DF & $\begin{array}{c}\text { Arch(5) test } \\
{[F \text { stat] }}\end{array}$ \\
\hline Observed & 0.0606 & 0.1527 & 1.1463 & 7.6152 & 157 & -17.98 & 19.2 \\
sample & {$[0.001]$} & & {$[0.000]$} & {$[0.000]$} & {$[0.000]$} & & {$[0.000]$} \\
GBM+RB & 0.0511 & 0.1479 & -0.0479 & 0.9198 & 57.3687 & -30.40 & 5.35 \\
+RV & {$[0.000]$} & & {$[0.53]$} & {$[0.000]$} & {$[0.000]$} & & {$[0.000]$} \\
\hline
\end{tabular}




\footnotetext{
${ }^{\text {i }}$ See Carrasquilla (1997a and 1997b).

ii Some "dirty" intervention is sometimes executed within the band by some Central banks for different purposes such as lowering the rate's volatility or affecting its short run tendency.

iii An implicit band was established in November 1991.

iv The new Constitution (1991) determined as the main responsibility of the Central Bank, Banco de la República, the preservation of the purchasing power of the citizens of the country - that is, lowering the inflation rate. See Regimen de Cambios Internacionales de Colombia 1997, Banco de la República, 1997.

${ }^{v}$ It should be noted that from September 1999, the exchange rate was allowed to float freely.

${ }^{\text {vi }}$ Flood and Garber (1989) have shown that the reduction of the conditional variance of the exchange rate works to the detriment of the interest rate's volatility. In Colombia's case, the Monetary Authorities tried to reduce such a phenomenon by introducing the interest rate range. However, it seems that this was done at the expense of increasing monetary base dispersion.

${ }^{v i i}$ Trading increased from a daily turnover average of US\$48 million in 1994 to US\$185 million in the first quarter of 1998.
}

viii Potential drawbacks from the methodology used to estimate our solutions result from our discrete approximation to the continuous time stochastic process and the use of a simple grid search algorithm, which may not reach a global minimum. 